\section{JURNAL EKONOMI EFEKTIF}

ISSN : $2622-8882$, E-ISSN : 2622-9935

Jurnal Ekonomi Efektif, Vol. 2, No. 4, Juli 2020

@ Prodi Manajemen Fakultas Ekonomi Universitas

Pamulang

\title{
PENGARUH CAPITAL ADEQUACY RATIO TERHADAP RETURN ON ASSET PADA PT. BANK CENTRAL ASIA, TBK PERIODE 2010-2019
}

\author{
Sri Retnaning Sampurnaningsih \\ Universitas Pamulang, Tangerang Selatan, Banten, Indonesia \\ *dosen01366@unpam.ac.id
}

\begin{abstract}
ABSTRAK
Penelitian ini bertujuan untuk mengetahui pengaruh Loan to Deposit Ratio terhadap Return on Asset pada PT Bank Central Asia, Tbk. Metode yang digunakan adalah explanatory research. Teknik analisis menggunakan analisis statistik dengan pengujian regresi, korelasi, determinasi dan uji hipotesis. Hasil penelitian ini variabel Loan to Deposit Ratio diperoleh nilai rata-rata sebesar 70,34\%. Variabel Loan to Deposit Ratio diperoleh nilai rata-rata 2,86\%. Loan to Deposit Ratio berpengaruh positif dan signifikan terhadap Return on Asset dengan nilai persamaan regresi $\mathrm{Y}=1,464+0,020 \mathrm{X}$, dan nilai koefisien korelasi 0,923 atau memiliki tingkat hubungan yang sangat kuat dengan nilai determinasi $85,2 \%$. Uji hipotesis diperoleh signifikansi $0,000<0,05$.
\end{abstract}

\section{Kata Kunci: Loan to Deposit Ratio, Loan to Deposit Ratio.}

\section{ABSTRACT}

This study aims to determine the effect of the Loan to Deposit Ratio on the Return on Assets at PT Bank Central Asia, Tbk. The method used is explanatory research. The analysis technique uses statistical analysis with regression testing, correlation, determination and hypothesis testing. The results of this study, the Loan to Deposit Ratio variable obtained an average value of $70.34 \%$. The Loan to Deposit Ratio variable obtained an average value of 2.86\%. Loan to Deposit Ratio has a positive and significant effect on Return on Assets with a regression equation value of $Y=1.464+0.020 X$, and a correlation coefficient value of 0.923 or has a very strong level of relationship with a determination value of $85.2 \%$. Hypothesis testing obtained a significance of $0.000<0.05$.

Keywords: Loan to Deposit Ratio, Loan to Deposit Ratio. 


\section{PENDAHULUAN}

\section{A. Latar Belakang Masalah}

Bank adalah suatu lembaga yang bergerak dibidang jasa yang menyediakan jasa keuangan bagi seluruh kalangan masyarakat. Fungsi utamanya ialah menghimpun dana dari masyarakat dan menyalurkan dana kepada masyarakat dengan berbagai tujuan atau disebut finansial intermediary. Kepercayaan masyarakat merupakan suatu hal yang sangat penting untuk perusahaan, tak terkecuali bank, karena dengan tingkat kepercayaan masyarakat yang tinggi terhadap suatu bank maka akan membuat masyarakat tertarik untuk menghimpun dana nya ke bank tersebut.

Dalam menganalisis kinerja keuangan perbankan khususnya profitabilitas, dapat dilakukan analisis rasio keuangan seperti Capital Adequacy Ratio (CAR), Loan To Deposit Ratio (LDR), Non Performing Loan (NPL), Biaya Operasional Pendapatan Operasional (BOPO), Net Interest Margin (NIM), Dana Pihak Ketiga (DPK), Financing to Deposit Ratio (FDR) dan lain sebagainya.

Variabel dependen (Variabel Y) dalam penelitian ini adalah aspek profitabilitas yang diukur dengan ROA. Loan to Deposit Ratios (ROA) merupakan rasio yang menunjukkan hasil atas jumlah aktiva yang digunakan dalam perusahaan (Kasmir, 2014). ROA diukur dari kemampuan perusahaan dalam menghasilkan laba dengan seluruh asetnya (Husnan dan Pudjiastuti, 2006:74). Dengan demikian, Loan to Deposit Ratios merupakan rasio yang menunjukkan hasil dari jumlah asset yang digunakan dalam perusahaan atau suatu ukuran tentang efisiensi manajemen. ROA menunjukkan hasil dari seluruh asset yang dikendalikan dengan mengabaikan sumber pendanaan. Biasanya nilai ROA disajikan dalam bentuk persentase.

Tujuan utama operasional bank adalah memperoleh tingkat profitabilitas yang tinggi. Profitabilitas adalah hasil bersih dari sejumlah kebijakan dan keputusan perusahaan (Lukitasari \& Kartika, 2015). Profitabilitas yang digunakan dalam penelitian ini adalah ROA (Loan to Deposit Ratio), karena ROA sangat penting bagi bank untuk mengukur efektivitas perusahaan dalam menghasilkan profit yang berkaitan dengan ketersediaan aset perusahaan. Semakin besar nilai ROA maka semakin besar pula tingkat keuntungan yang dicapai bank tersebut.

Profitabilitas merupakan salah satu faktor untuk menilai baik buruknya kinerja perusahaan. Loan to Deposit Ratios (ROA) merupakan rasio profitabilitas yang digunakan untuk mengukur efektivitas perusahaan di dalam menghasilkan keuntungan dengan memanfaatkan total aktiva yang dimilikinya. Adapun faktor-faktor yang dapat mempengaruhi profitabilitas suatu perusahaan diantaranya Loan to Deposit Ratio (CR), Total Assets Turnover (TATO), Debt To Equity Ratio (DER), Debt Ratio (DR), Pertumbuhan Penjualan dan Ukuran Perusahaan. Di dalam penelitian ini menggunakan LDR sebagai faktor-faktor yang mempengaruhi profitabilitas.

Tabel 1. Nilai LRD dan ROA PT. Bank Central Asia Tbk Tahun 2010-2019

\begin{tabular}{|c|c|c|}
\hline Tahun & LDR & ROA \\
\hline 2010 & 50,22 & 2,41 \\
\hline 2011 & 55,11 & 2,61 \\
\hline 2012 & 61,27 & 2,83 \\
\hline 2013 & 68,36 & 2,65 \\
\hline 2014 & 74,93 & 2,87 \\
\hline
\end{tabular}




\begin{tabular}{|c|c|c|}
\hline 2015 & 75,93 & 2,99 \\
\hline 2016 & 79,89 & 3,03 \\
\hline 2017 & 76,68 & 3,05 \\
\hline 2018 & 77,96 & 3,11 \\
\hline 2019 & 83,06 & 3,13 \\
\hline Rata-rata & & \\
\hline
\end{tabular}

Idealnya perusahaan disamping memiliki kemampuan

PT Bank Central Asia Tbk Tahun 2010-2019 dibarengi dengan meningkatnya nilai profitabilitas (Loan to Deposit Ratio). Oleh sebab itu PT Bank Central Asia Tbk Tahun 2010-2019 di tuntut untuk memanfaatkan (Capital Adequacy Ratio) dengan baik. Dalam mengelola modal dan keuangan yang dimilikinya secara efektif dan efisien dengan mengelola kecukupan modal dan meningkatkan laba profitabilitas (Loan to Deposit Ratio) serta memenuhi kewajiban jangka pendek nya (Loan to Deposit Ratio). Nilai Capital Adequacy Ratio dan Loan to Deposit Ratio PT Bank Central Asia Tbk tahun 2010-2019 kurang stabil dengan peningkatan Loan to Deposit Ratio dan Capital Adequacy Ratio yang terjadi. Sebaliknya, PT Bamk Central Asia Tbk naik turun pendapatan disetiap tahunnya.

Selain fenomena di atas, penelitian ini juga dilatar belakangi oleh adanya research gap dari hasil temuan peneliti-peneliti terdahulu yang meneliti mengenai faktor-faktor yang mempengaruhi Kinerja Keuangan.

Pengukuran Likuiditas dengan menggunakan pengukuran rasio LDR atau Loan to Deposit Ratio yang diteliti oleh Defri (2012) dan Buchory (2014) menyimpulkan bahwa LDR atau Loan to Deposit Ratio berpengaruh signifikan positif terhadap profitabilitas. Sedangkan menurut Hariemufti (2015) menyimpulkan bahwa LDR tidak signifikan berpengaruh terhadap profitabilitas.

Dengan adanya fenomena-fenomena yang terjadi dan juga research gap yang terjadi pada peneliti-peneliti sebelumnya mengenai hasil temuan yang tidak konsisten terhadap faktor-faktor yang mempengaruhi Kinerja Keuangan pada bank. Oleh karena itu atas dasar tersebut, peneliti tertarik untuk melakukan penelitian kembali dan menguji kembali mengenai "Pengaruh Loan to Deposit Ratio (LDR) Terhadap Return on Asset (ROA) Pada PT Bank Central Asia Tbk Tahun Periode 2010-2019".

\section{B. Rumusan Masalah}

1. Bagaimana Loan to Deposit Ratio pada PT Bank Central Asia, Tbk?.

2. Bagaimana Return on Asset pada PT Bank Central Asia, Tbk ?.

3. Adakah pengaruh antara Loan to Deposit Ratio terhadap Return on Asset pada PT Bank Central Asia, Tbk?.

\section{Tujuan Penelitian}

1. Untuk mengetahui kondisi Loan to Deposit Ratio pada PT Bank Central Asia, Tbk.

2. Untuk mengetahui kondisi Return on Asset pada PT Bank Central Asia, Tbk.

3. Untuk mengetahui pengaruh antara Loan to Deposit Ratio terhadap Return on Asset pada PT Bank Central Asia, Tbk.

\section{METODE PENELITIAN}

\section{Populasi}

Populasi dalam penelitian ini laporan keuangan PT Bank Central Asia, Tbk selama 10 tahun 


\section{Sampel}

Teknik pengambilan sampling dalam penelitian ini adalah samplel jenuh, dimana semua anggota populasi dijadikan sebagai sampel. Dengan demikian sampel dalam penelitian ini laporan keuangan PT Bank Central Asia, Tbk selama 10 tahun.

\section{Jenis Penelitian}

Jenis penelitian yang dipakai adalah asosiatif, dimana tujuannya adalah untuk mengetahui mencari keterhubungan antara variabel independen terhadap variabel dependennya

\section{Metode Analisis Data}

Dalam menganalisis data digunakan uji validitas, uji reliabilitas, analisis regresi linier sederhana, koefisien korelasi, koefisien determinasi dan uji hipotesis.

\section{HASIL PENELITIAN}

\section{Analisis Deskriptif}

Pada pengujian ini digunakan untuk mengetahui skor minimum dan maksimum skor tertinggi, ratting score dan standar deviasi dari masing-masing variabel. Adapun hasilnya sebagai berikut:

Tabel 1. Hasil Analisis Descriptive Statistics

\begin{tabular}{lr|r|r|r|r} 
& \multicolumn{2}{c}{ Descriptive Statistics } & \\
& $N$ & Minimum & Maximum & \multicolumn{1}{c}{ Mean } & \multicolumn{1}{c}{ Std. Deviation } \\
\hline LDR & 10 & 50.22 & 83.06 & 70.3410 & 11.18794 \\
\hline ROA & 10 & 2.41 & 3.13 & 2.8680 & .24193 \\
\hline Valid N (listwise) & 10 & & & & \\
\hline
\end{tabular}

Loan to Deposit Ratio diperoleh nilai minimum sebesar 50,22\% dan nilai maximum 83,06\% dengan rata-rata sebesar 70,34\% dengan standar deviasi $11,187 \%$.

Sedangkan nilai Return on Asset diperoleh nilai minimum sebesar 2,4\% dan nilai maximum $3,13 \%$ dengan rata-rata sebesar $2,86 \%$ dengan standar deviasi $24,419 \%$.

\section{Analisis Verifikatif.}

Pada analisis ini dimaksudkan untuk mengetahui pengaruh variabel independen terhadap variabel dependen. Adapun hasil pengujian sebagai berikut:

\section{a. Analisis Regresi Linier Sederhana}

Uji regresi ini dimaksudkan untuk mengetahui perubahan variabel dependen jika variabel independen mengalami perubahan. Adapun hasil pengujiannya sebagai berikut:

Tabel 2. Hasil Pengujian Regresi Linier Sederhana

\begin{tabular}{|c|c|c|c|c|c|c|}
\hline \multicolumn{7}{|c|}{ Coefficients $^{a}$} \\
\hline \multirow{2}{*}{\multicolumn{2}{|c|}{ Model }} & \multicolumn{2}{|c|}{$\begin{array}{l}\text { Unstandardized } \\
\text { Coefficients }\end{array}$} & \multirow{2}{*}{$\begin{array}{c}\text { Standardized } \\
\text { Coefficients } \\
\text { Beta }\end{array}$} & \multirow[b]{2}{*}{$\mathrm{t}$} & \multirow[b]{2}{*}{ Sig. } \\
\hline & & $\mathrm{B}$ & Std. Error & & & \\
\hline 1 & (Constant) & 1.464 & .209 & & 7.003 & .000 \\
\hline & LDR & .020 & .003 & .923 & 6.795 & .000 \\
\hline
\end{tabular}

a. Dependent Variable: ROA

Berdasarkan hasil pengujian pada tabel di atas, diperoleh persamaan regresi $\mathrm{Y}=$ $1,464+0,020 X$. Dari persamaan tersebut dijelaskan sebagai berikut:

1) Konstanta sebesar 1,464 diartikan jika Loan to Deposit Ratio tidak ada, maka telah terdapat nilai Return on Asset sebesar 1,464 point.

2) Koefisien regresi Loan to Deposit Ratio sebesar 0,020, angka ini positif artinya setiap ada peningkatan Loan to Deposit Ratio sebesar 0,020 point maka Return on Asset 
juga akan mengalami peningkatan sebesar 0,020 point.

\section{b. Analisis Koefisien Korelasi}

Analisis koefisien korelasi dimaksudkan untuk mengetahui tingkt kesangat kuatan hubungan dari variabel independen terhadap variabel dependen baik secara parsial maupun simultan. Adapun hasil pengujian sebagai berikut:

Tabel 3. Hasil Pengujian Koefisien Korelasi Loan to Deposit Ratio Terhadap Return on Asset.

\begin{tabular}{|c|c|c|c|}
\hline \multicolumn{4}{|c|}{ Correlations $^{b}$} \\
\hline & & LDR & ROA \\
\hline \multirow[t]{2}{*}{$\overline{L D R}$} & Pearson Correlation & 1 & $.923^{* *}$ \\
\hline & Sig. (2-tailed) & & .000 \\
\hline \multirow{2}{*}{ ROA } & Pearson Correlation & $.923^{* *}$ & 1 \\
\hline & Sig. (2-tailed) & .000 & \\
\hline
\end{tabular}

\section{c. Analisis Koefisien Determinasi}

Analisis koefisien determinasi dimaksudkan untuk mengetahui besarnya persentase pengaruh dari variabel independen terhadap variabel dependen. Adapun hasil pengujian sebagai berikut:

Tabel 4. Hasil Pengujian Koefisien Determinasi Loan to Deposit Ratio Terhadap Return on Asset.

\begin{tabular}{|c|c|c|c|c|}
\hline \multicolumn{5}{|c|}{ Model Summary } \\
\hline Model & $\mathrm{R}$ & R Square & $\begin{array}{l}\text { Adjusted R } \\
\text { Square }\end{array}$ & $\begin{array}{l}\text { Std. Error of the } \\
\text { Estimate }\end{array}$ \\
\hline 1 & $.923^{a}$ & .852 & .834 & .09861 \\
\hline
\end{tabular}

Berdasarkan hasil pengujian diperoleh nilai determinasi sebesar 0,852 artinya Loan to Deposit Ratio memiliki kontribusi pengaruh sebesar 85,2\% terhadap Return on Asset, sedangkan sisanya sebesar $14,8 \%$ dipengaruhi faktor lain.

\section{d. Uji Hipotesis}

Pengujian hipotesis dengan uji $\mathrm{t}$ digunakan untuk mengetahui hipotesis mana yang diterima.

Rumusan hipotesis: Terdapat pengaruh yang signifikan antara Loan to Deposit Ratio terhadap Return on Asset.

Tabel 5. Hasil Uji Hipotesis Loan to Deposit Ratio Terhadap Return on Asset.

\begin{tabular}{|c|c|c|c|c|c|c|}
\hline \multicolumn{7}{|c|}{ Coefficients $^{a}$} \\
\hline \multirow{2}{*}{\multicolumn{2}{|c|}{ Model }} & \multicolumn{2}{|c|}{$\begin{array}{l}\text { Unstandardized } \\
\text { Coefficients }\end{array}$} & \multirow{2}{*}{$\begin{array}{c}\text { Standardized } \\
\text { Coefficients } \\
\text { Beta }\end{array}$} & \multirow[b]{2}{*}{$\mathrm{t}$} & \multirow[b]{2}{*}{ Sig. } \\
\hline & & $\mathrm{B}$ & Std. Error & & & \\
\hline 1 & (Constant) & 1.464 & .209 & & 7.003 & .000 \\
\hline & LDR & .020 & .003 & .923 & 6.795 & .000 \\
\hline
\end{tabular}

a. Dependent Variable: ROA

Berdasarkan hasil pengujian pada tabel di atas, diperoleh nilai $t$ hitung $>\mathrm{t}$ tabel 
atau $(6,795>2,306)$, dengan demikian hipotesis yang diajukan bahwa terdapat pengaruh yang signifikan atara Loan to Deposit Ratio terhadap Return on Asset diterima.

\section{Pembahasan Hasil Penelitian}

\section{Kondisi Nilai Loan to Deposit Ratio}

Berdasarkan data empiris dan analisis data, variabel Loan to Deposit Ratio diperoleh nilai rata-rata per tahun sebesar $70,34 \%$.

\section{Kondisi Nilai Return on Asset}

Berdasarkan data empiris dan analisis data, variabel Return on Asset diperoleh nilai ratarata per tahun sebesar $2,86 \%$.

\section{Pengaruh Loan to Deposit Ratio Terhadap Return on Asset}

Loan to Deposit Ratio berpengaruh signifikan terhadap Return on Asset dengan persamaan regresi $\mathrm{Y}=1,464+0,020 \mathrm{X}$, nilai korelasi sebesar 0,923 atau memiliki hubungan yang sangat kuat dengan kontribusi pengaruh sebesar 85,2\%, sedangkan sisanya sebesar $14,8 \%$ dipengaruhi faktor lain. Pengujian hipotesis diperoleh nilai $t$ hitung $>t$ tabel atau $(6,795>2,306)$. Dengan demikian hipotesis yang diajukan bahwa terdapat berpengaruh signifikan antara Loan to Deposit Ratio terhadap Return on Asset diterima.

\section{KESIMPULAN DAN SARAN}

1. Kesimpulan

a. Kondisi variabel Loan to Deposit Ratio berdasar pada periode laporan keuangan 10 tahun diperoleh Loan to Deposit Ratio rata-rata sebesar 70,34\%.

b. Kondisi variabel Loan to Deposit Ratio berdasar pada periode laporan keuangan 10 tahun diperoleh Loan to Deposit Ratio rata-rata sebesar 2,86\%.

c. Loan to Deposit Ratio berpengaruh signifikan terhadap Return on Asset dengan persamaan regresi $\mathrm{Y}=1,464+0,020 \mathrm{X}$, nilai korelasi sebesar 0,923 atau sangat kuat dan kontribusi pengaruh sebesar $85,2 \%$ sedangkan sisanya sebesar $14,8 \%$ dipengaruhi faktor lain. Uji hipotesis diperoleh nilai $t$ hitung $>\mathrm{t}$ tabel atau $(6,795>2,306)$.

\section{Saran}

a. Pihak manajemen bank agar lebih memperhatikan likuiditas dan menjaga keseimbangan modal perusahaan pada bank dan lebih meningkatkan perolehan capitalnya dalam kegiatannya.

b. Tingkat LDR masih belum mencapai standar yang telah ditetapkan oleh perusahaan. Kiranya pihak perbankan perlu mempertimbangkan aspek Biaya Operasional yang dikeluarkan dan meningkatkan kembali Pendapatan yang masuk guna meminimalisir resiko suatu perusahaan perbankan.

c. Bagi peneliti selanjutnya disarankan untuk melakukan penelitian di luar 561ariable 561 ariable561nt yang digunakan dalam penelitian ini ataupun mengkombinasikan salah satu vaiabel dalam penelitian ini dengan vaiabel lain diluar 561ariable dalam penelitian ini, agar dapat memperoleh hasil yang lebih bervariatif yang dapat menggambarkan hal-hal apa saja yang dapat berpengaruh terhadap Return on Assets.

\section{DAFTAR PUSTAKA}

Agus Harjito \& Martono, (2010) "Manajemen Keuangan" Yogyakarta: Penerbit Ekonisia. Agus Sartono. (2010). "Manajemen Keuangan Toeri dan Aplikasi", Edisi keempat, 
Yogyakarta: Penerbit BPFE.

Algifari. (2015). “Analisis Regresi untuk Bisnis dan Ekonomi”. Yogyakarta: BPFE.

Arikunto, Suharsimi (2014). "Prosedur Penelitian Suatu Pendekatan Praktek". Jakarta: Rineka Cipta.

Bambang Riyanto, (2011). "Dasar-dasar Pembelanjaan Perusahaan”. Edisi ke empat, BPFE Yogyakarta.

Fahmi, Irham (2012), "Pengantar Manajemen Keuangan” Cetakan pertama. Bandung: Penerbit Alfabeta.

Imam Ghozali (2017). “Aplikasi Analisis Multivariate Dengan Program SPSS”. Edisi Kelima. Semarang: Badan Penerbit Undip.

Istijanto (2014) "Riset Sumber Daya Manusia”. Jakarta: PT. Gramedia Pustaka

Ilham, D. (2014). Implementasi Nilai-Nilai Keagamaan pada Mata Pelajaran Umum dalam

Upaya Peningkatan Akhlak Peserta Didik di MAN Malili Kabupaten Luwu

Timur (Doctoral dissertation, STAIN/IAIN Palopo).

Ilham, D. (2019). Implementing Local Wisdom Values in Bride and Groom Course at KUA Bara SubDistrict, Palopo City. Jurnal Konsepsi, 8(1), 1-9.

Ilham, D. (2019). Menggagas Pendidikan Nilai dalam Sistem Pendidikan

Nasional. Didaktika: Jurnal Kependidikan, 8(3), 109-122.

Jasmani, J. (2018). Pengaruh Kinerja Keuangan Terhadap Harga Saham (Analisis Pada Perusahaan Property dan Real Estate Yang Go Public di Bursa Efek Indonesia. Jurnal Akuntansi Indonesia, 12(2).

Jasmani, J. (2019). The Effect of Liquidity and Working Capital Turnover on Profitability at PT. Sumber Cipta Multiniaga, South Jakarta. PINISI Discretion Review, 3(1), 29-38.

Kasmir (2010), "Analisis Laporan keuangan”, penerbit raja grafindo persada, Jakarta

Kasmir, (2010). "Pengantar Manajemen Keuangan”, Edisi Pertama, Cetakan kedua, Jakarta: Penerbit Prenada Media.

Kasmir. (2012) "Pengantar Manajemen Keuangan”, Edisi Pertama, Cetakan kedua, Jakarta: Prenada Media.

Kharis, Ismu Fadli (2011). "Studi Mengenai Impulse Buying dalam Penjualan Online". Semarang : Skripsi Universitas Diponegoro

Martono dan Agus Harjito, (2011). "Manajemen Keuangan”, Jakarta: Penerbit Ekonisia.

Munawir (2010), "Analisis Laporan Keuangan", Edisi Ke Empat, Penerbit Liberty, Yogyakarta.

Santoso, Singgih (2015). "Menguasai Statistik Multivariat". Jakarta: PT Elex Media Komputindo.

Sartono, "Manajemen Keuangan Aplikasi Dan Teori", Edisi Keempat, BPFE, Yogyakarta, 2008.

Sawir, (2003). “Analisis Kinerja Keuangan dan Perencanaan Keuangan Perusahaan”, Cetakan ketiga, Jakarta: Penerbit PT. Gramedia Pustaka Utama.

Sugiyarso, G. dan F. Winarni, "Manajemen Keuangan (Pemahaman Laporan Keuangan, Pengelolaan Aktiva, Kewajiban dan Modal serta Pengukuran

Sugiyono (2017), "Metode Penelitian Administrasi : dilengkapi dengan Metode R \& D". Bandung: Alfabeta.

Sunarsi, D., \& Baharuddin, A. (2019). The Effect of Service Quality and Price Accuracy on Consumer Confidence and Implications for Sales Increase. PINISI Discretion Review, 3(2), 101-110. 